\begin{tabular}{|c|l|}
\hline Title & $\begin{array}{l}\text { Hydrothermal system beneath the crater of Tarumai volcano, Japan : 3-D resistivity structure revealed using audio- } \\
\text { magnetotellurics and induction vector }\end{array}$ \\
\hline Author(s) & Y amaya, Y usuke; Mogi, Toru; Hashimoto, Takeshi; Ichihara, Hiroshi \\
\hline Citation & $\begin{array}{l}\text { Journal of Volcanology and Geothermal Research, 187(3-4), 193 202 } \\
\text { https:/doi.org/10.1016/.jvolgeores.2009.09.008 }\end{array}$ \\
\hline Issue Date & 2009-11-10 \\
\hline Doc URL & http://hdl.handle.net/2115/40047 \\
\hline Type & article(author version) \\
\hline File Information & JVGR187-3-4_193-202.pdf \\
\hline
\end{tabular}

Instructions for use 


\title{
Hydrothermal system beneath the crater of Tarumai volcano, Japan: 3-D resistivity structure revealed using audio-magnetotellurics and induction vector
}

\author{
Yusuke Yamaya ${ }^{\text {a, }}$, Toru Mogi ${ }^{a}$, Takeshi Hashimoto ${ }^{a}$ and Hiroshi Ichihara ${ }^{b, c}$ \\ ${ }^{a}$ Institute of Seismology and Volcanology, Hokkaido University, N10W8, Kita-ku, Sapporo, 060-0810, Japan \\ b Institute for Research on Earth Evolution, Japan Agency for Marine-Earth Science and Technology, 2-15 Natsushima-Cho, \\ Yokosuka, Kanagawa 273-0061, Japan. \\ ${ }^{\mathrm{c}}$ Earthquake Research Institute, University of Tokyo, 1-1-1, Yayoi, Bunkyo-ku, Tokyo, 113-0032, Japan
}

"Corresponding author: Institute of Seismology and Volcanology, Hokkaido University, N10W8, Kita-ku, Sapporo, 060-0810, Japan E-mail address: yamayama@mail.sci.hokudai.ac.jp (Y. Yamaya)

\begin{abstract}
Audio-magnetotelluric (AMT) measurements were recorded in the crater area of Tarumai volcano, northeastern Japan. This survey brought the specific structures beneath the lava dome of Tarumai volcano, enabling us to interpret the relationship between the subsurface structure and fumarolic activity in the vicinity of a lava dome. Three-dimensional resistivity modeling was performed to achieve this purpose. The measured induction vectors pointed toward the center of the dome, implying the topographic effect. However, estimation of the topographic effect showed that the measured vector was not explained only by this effect. This suggested that the distribution of induction vectors still held information of the subsurface structure and could be helpful in determining the geometry of 3-D bodies. The 3-D modeling was based on a quasi-one-dimensional layered structure that included topography. The final model revealed that the andesitic lava dome is characterized by comparatively low resistivity $(50 \Omega \mathrm{m})$, and that two conductive bodies (50 and 1-5 $\Omega \mathrm{m})$ are present beneath the lava dome. The shallower of these conductors is interpreted as an aquifer, such as a buried crater lake. The deeper, extremely conductive body corresponded to a convecting zone containing rising hydrothermal fluid. The shallower aquifer critically controls the temperature and chemical components of the fumarolic gasses. High-temperature gas supplied from deeper part that encounters the shallow aquifer loses its water-soluble components and heat, resulting in weak and low-temperature fumaroles. In contrast, most of the gas, which ascends outside the area of the shallower aquifer, is released as high-temperature fumaroles. This study provides an insight that the shallow aquifer in the crater area plays a significant role in the property of fumaroles at the volcanic surface.
\end{abstract}

Keywords: lava dome; magnetotelluric; electrical resistivity; Tarumai 


\section{Introduction}

The three-dimensional (3-D) resistivity structure beneath an active volcano can provide information about the location and transport path of volcanic fluids, because the resistivity of rocks is effectively varied by the existence of fluids, hydrothermal alteration and temperature. The distribution and behavior of volcanic fluids such as magma, volcanic gas, and hydrothermal fluids are unique to each volcano. For example, understanding the phreatic explosions that result when magma contacts a shallow aquifer (e.g., Kagiyama et al., 1999) requires data on the position and volume of the aquifer. Investigating the 3-D resistivity structure of a volcano can identify the depth and position of such aquifers, contributing to our understanding of hydrothermal condition beneath volcanoes.

Fumarolic activity of Tarumai volcano, located in northeastern Japan, has been constant on and around a lava dome that formed in the crater area during the 1909 eruption. Fumaroles occupy an area approximately $500 \mathrm{~m}$ in diameter. Fumaroles located on the southern part of the dome emit particularly high-temperature gases that reach $600{ }^{\circ} \mathrm{C}$ (Sapporo District Meteorological Observatory, 2004), suggesting that they degas directly from magma. The temperature of other fumaroles, however, is below the boiling point of water. Such spatial differences in fumarolic temperature may be a function of the subsurface structure beneath the fumaroles. Taking this assumption into consideration, audio-magnetotelluric (AMT) soundings were conducted at densely spaced sites to delineate the 3-D resistivity structure of the subsurface.

This paper treats electrical resistivity as a parameter that reflects the 3-D subsurface structure. MT soundings have been successfully used at many volcanic and geothermal areas to reveal hydrothermal convection systems and magma reservoirs (e.g., Matsushima et al., 2001; Aizawa et al., 2008; Kanda et al., 2008). MT soundings have also been used to locate volcanic fluid paths (e.g., Nurhasan et al., 2006). Such studies have generally analyzed MT data using inversions and assuming a two-dimensional (2-D) structure. The 2-D assumption, however, can be a problem when investigating volcanoes because of the effect of surface topography. The topographic effect on MT data is quite different between 2-D and 3-D topography (Nam et al., 2007); thus using a 2-D assumption for 3-D topography can provide misleading results in the resulting resistivity model. Another problem is determining the strike of a 2-D structure. Techniques for estimating an electromagnetic 2-D strike, such as Groom-Bailey's decomposition (Groom and Bailey, 1989) and the phase-tensor technique (Caldwell et al., 2004), commonly do not yield a consistent 2-D strike direction. This indicates that the assumption of 2-D structure is not appropriate for such study areas. Three-dimensional analyses overcome such problems. As a result of improved computing technology, the computing time for 3-D numerical modeling has recently decreased, and 3-D forward modeling is now widely used. However, 3-D forward modeling that incorporates surface topography remains uncommon (e.g., Mogi and Nakama, 1993; Müller and Haak, 2004), and few studies of the 3-D resistivity structure of volcanoes have used a numerical inversion technique (e.g., Jones et al., 2008). This has been caused by working cost to obtain denser measurements for 3-D modeling and long duration to calculate the response including surface topography. The AMT soundings that target shallow structure, however, can be measured by comparatively lightweight instruments and require only a few hours per a station. As the computation time has been shortened practical level, 3-D modeling is now becoming more popular than before. Such a 3-D modeling should be applied proactively to volcanic areas. To obtain the knowledge of 3-D subsurface 
structure, this study applied 3-D resistivity modeling to AMT data for the crater area of Tarumai volcano.

In this study, the induction vector is used in the modeling as well as the ordinary impedance tensor, aiming for fleeing the static shift. We show the usefulness of the induction vector in 3-D modeling with steep topography. Based on our resistivity model, structural control of fumarolic activity around the lava dome is discussed.

\section{The lava dome of Tarumai volcano and its surroundings}

Tarumai is an active andesitic volcano located in southwestern Hokkaido, northeastern Japan. It is one of several volcanoes that formed along the southeast wall of Shikotsu caldera, which formed approximately $30 \mathrm{ka}$ (Katsui, 1963). The lava dome, one of the most obvious features of Tarumai, is located beside a pyroclastic cone in the summit crater area. As recorded in historical descriptions of past eruptions (Ishikawa et al., 1972), such a dome was generated and destroyed at least twice. The present dome formed during the 1909 eruption, which was the most recent magmatic eruption. The present dome formed as a result of magma squeezing through a vent (Yokoyama, 2004). Some phreatic eruptions after the 1909 event partly fractured the dome, forming two fissures that trend NE and NW (Fig. 1).

Volcanic gas emission around the lava dome is conspicuous. In recent decades, volcanic gas from the A crater and $\mathrm{B}$ fumaroles has had extremely high temperature (up to $600^{\circ} \mathrm{C}$ ), whereas temperatures at other fumaroles have been below the boiling point of water (Sapporo District Meteorological Observatories, 2004). Such temperature contrasts over short distances are probably related to hydrothermal activity beneath the dome. Aoyama et al. (2004) and Aoyama (2006) suggested that hydrothermal water beneath the volcano may have contributed to a low-frequency earthquake swarm that was triggered by the 2003 Tokachi-oki earthquake ( $\mathrm{Mw} \mathrm{8.0)}$ beneath the volcano, after which gas emission took place at the B fumaroles (e.g., Terada et al., 2004).

Resistivity investigations focusing on the structure beneath the lava dome have been conducted (Watanabe et al., 1984; Sapporo District Meteorological Observatories, 1999). A dipole-dipole resistivity survey by Watanabe et al. (1984) showed that the resistivity decreases monotonously with depth, and the resistivity structure beneath the lava dome has almost the same structure as that beneath the southern part of the crater area at several hundred meters depth. A later study (Sapporo District Meteorological Observatories, 1999) confirmed that finding and also identified a resistivity structure consisting of four layers. These investigations, however, were based on DC resistivity sounding that assumed a horizontally layered structure (1-D analysis) and did not include the top of the dome. A 3-D analysis with denser AMT measurements will offer new insight into the subsurface structure in the crater area of Tarumai volcano.

\section{AMT survey and data processing}

Audio-frequency magnetotellurics measures electromagnetic variation of the audio-frequency band (approximately 1 to $10^{4} \mathrm{~Hz}$ ). Using this frequency band provides information on the resistivity structure to depths of a few kilometers. Figure 1 shows the distribution of the AMT measurement 
sites in the crater area of Tarumai. For the 3-D analysis, measurements were made on a grid at approximately 200-m spacing. Time-series data for the electric and magnetic fields were collected using the MTU-5A system manufactured by Phoenix Geophysics, Ltd. (Canada). Pb-PbCl $\mathrm{Pb}_{2}$ electrodes and induction coils were used to measure two horizontal components of the electric fields and three components of the magnetic fields, respectively. Time-series data were collected for a few hours at each site and then transformed to power spectra using a Fourier transformation. The remote reference technique (Gamble et al., 1979) was applied for eight AMT sites for which time-series data had been simultaneously measured at the site 290, locating about $2 \mathrm{~km}$ north from the study area (Fig. 1b). Remote site is generally placed at great distance where the noise is incoherent with that in the survey area, in order to reduce bias in response function. Given the skin depth corresponding to the AMT band, although the distance of $2 \mathrm{~km}$ in this study might be too close, the results of processing improved quality particularly in frequency ranges around 50 and $2000 \mathrm{~Hz}$. The sites A30 and A40 were processed with each other. In spite of close range between these sites, the remote reference process was effective in the same frequency ranges. The other 10 sites, which did not have any remote data, were compelled to process by single site. The apparent resistivity, impedance phase, and induction vectors were calculated from the MT impedances, which were derived from the power spectra at each frequency, at each site.

The apparent resistivity trend was approximately the same at all sites, decreasing as frequency decreased (Fig. 5). Although such behavior might suggest a simple layered structure, the real part of the induction vectors pointed toward the northeastern part of the dome at a frequency range above $100 \mathrm{~Hz}$ (Fig. 2), implying the presence of a conductor within or below the dome. In order to estimate the dimensions of the structure, phase tensors were calculated (Caldwell et al., 2004). Figure 2 shows the distributions of the phase tensors for each frequency. The major axis of the phase tensors was concentrated toward the center of the lava dome at 1000 and $100 \mathrm{~Hz}$, but lacked any discernable trend at other frequencies. The skew angle $(\beta)$ of the phase tensors was large $\left(>10^{\circ}\right)$, indicating the existence of strong 3-D structures. This indicated that 3-D analysis would be more suitable than 1-D or 2-D analysis for modeling the structure of the study area.

\section{Three-dimensional forward modeling}

\subsection{Model setting}

Three-dimensional forward modeling based on AMT data was performed to reveal the resistivity structure beneath the crater area, including the lava dome, using a part of wideband-MT data which was measured in another survey (Yamaya et al., 2005). Induction vectors could not be obtained for wideband-MT sites because only the electric field was measured.

The MT responses were calculated using the 3-D numerical modeling code developed by Fomenko and Mogi (2002). The modeling scheme is based on a finite-difference staggered grid of non-uniformly sized rectangles. Using a staggered grid yields highly accurate results, even for irregular grids. This decreases both the number of cells and the calculation time because small cells can be limited to areas of greatest interest near the conductivity breaks (Fomenko and Mogi, 2002). This scheme is, therefore, applicable to models with large resistivity contrasts and complicated topography.

The grid consists of X: $38 \times \mathrm{Y}: 39 \times \mathrm{Z}: 39$ (air: 17, ground: 22) = 57,798 cells. When the 
regional structure has two-dimensionality, the off-diagonal components ( $\mathrm{XY}$ and YX) of impedance tensor show their characteristics if they would be rotated to the direction of regional strike. Considering the above, the grid coordinates ( $\mathrm{X}$ and $\mathrm{Y}$ axes) are set to $\mathrm{N} 45^{\circ} \mathrm{W}$ and $\mathrm{N} 45^{\circ} \mathrm{E}$. These directions are parallel and perpendicular to the regional electromagnetic strike estimated from the wideband MT data (Yamaya et al., 2005) and correspond to the trend of fissures on and around the dome. This idea does not deny the three-dimensionality in the study area, but can make it easier to model the structure along the regional and surface strikes. The smallest block was X: $50 \mathrm{~m} \times \mathrm{Y}: 50$ $\mathrm{m} \times \mathrm{Z}: 10 \mathrm{~m}$, over the central area that includes the dome. Rectangle size increased with distance from the center. The entire model was X: $200 \mathrm{~km} \times \mathrm{Y}: 200 \mathrm{~km} \times \mathrm{Z}: 200 \mathrm{~km}$ (air: $100 \mathrm{~km}$, ground: $100 \mathrm{~km})$. MT responses were calculated at eight frequencies between 3600 and $0.35 \mathrm{~Hz}$.

\subsection{Estimation of the topographic effect}

The observed induction vectors pointed toward the center of the lava dome (Fig. 2). Even if its resistivity is the same as the surrounding ground, the lava dome is relatively more conductive than air, and thus induction vectors around the dome should point toward it. Müller and Haak (2004) identified this problem and resolved it by including topography in their model. Topography has a measurable effect even on apparent resistivity and the impedance phase. Nam et al. (2007) numerically calculated MT impedance from 3-D models that included topography consisting of a symmetrical hill. The assumed slope angle $\left(31^{\circ}\right)$ was as steep as the Tarumai dome $\left(28-35^{\circ}\right)$, and the calculated impedance change was significant (maximum $75 \%$ for apparent resistivity and $13 \%$ for phase at $2 \mathrm{~Hz}$; Nam et al., 2007). The effect increases if the slope angle increases. Thus, topography around the dome must be included.

The topographic effect of the dome was estimated by modeling its topography with blocks. Blocks $20 \mathrm{~m}$ high were added to the base surface of the model at $880 \mathrm{~m}$ (a.s.l.). The calculation was performed using a uniform resistivity of $100 \Omega \mathrm{m}$ for the ground, including the dome. Although the directions of the calculated induction vectors at $1000 \mathrm{~Hz}$ (Fig. 3a) were close to the expected values, magnitudes were not as large as the measured induction vectors. This tendency is especially clear at $100 \mathrm{~Hz}$ (Fig. 3a), where the calculated induction vectors were extremely small compared to the observed ones. This behavior did not seem to vary with changes in ground resistivity. At $1000 \mathrm{~Hz}$, however, some of the calculated vectors at a distance from the dome pointed in obviously different directions (area "N" and "H" in Fig. 3a). This result was due to attraction by the peaks of Nishiyama (NYP) or Higashiyama (HYP). Although topography certainly affects the estimated induction vectors, it is not adequate to explain the measured ones. Thus, because the measured vectors were not explained only by the surface topography, the induction vectors hold the information of the subsurface structure. The induction vectors, therefore, would be a useful parameter in modeling even where the topography is steep like this study area.

\subsection{Modeling}

Modeling was based on the method of Müller and Haak (2004), which consists of calculating a 1-D model for each site and then modifying these models to fit the induction vectors. The induction vector, which is calculated from only the magnetic fields, is free from the static shift that is one of the serious problem arising from the apparent resistivity. The static shift, which is due to small inhomogeneous structure near surface, causes a shift of an apparent resistivity curve. The advantage using the induction vector relieves us of the effects due to the static shift in the modeling. In 
addition, we can easily model a geometry and resistivity of a conductor because the vector points toward the direction of a conductor, and its magnitude depends on the contrast of resistivity.

The starting model for the 3-D forward calculation was based on a layered structure (Fig. 4) and applied the results of the 1-D inversions for each site in the crater area. Resistivity above the base surface (>880 $\mathrm{m}$ a.s.1.) was set equivalent to the uppermost layer (Fig. 4). The measured apparent resistivity and phase were generally matched at this stage, including the effects of topography and the layered structure. We here allowed the static shift for the apparent resistivity independently on the xy and yx components, and thus evaluated not the absolute value but the shapes of the sounding curves. The calculated apparent resistivity, which trends from high to low as the frequency decreases, confirmed the measured features, but significant disagreement between measured and calculated induction vectors remained. In the second modeling procedure, 3-D bodies were added to the layered structure to improve the fit of the induction vectors. The geometries and resistivities of these 3-D bodies were determined by trial and error, and a minimum number of such bodies was used in order to minimize ambiguity of the model. The induction vector proved to be a powerful parameter in building the model for this area, where the features of the apparent resistivities and impedance phases were quite similar at each site.

\subsection{Results}

The final model obtained through forward modeling is shown in Fig. 6, and the calculated induction vectors are shown in Fig. 3b. Figure 5 shows the calculated and measured sounding curves at representative sites. The statistical fit of the data was measured by the root mean-square (RMS) residual (Table 1). In order to evaluate it equally, we introduced an error-weighted RMS, with giving equivalent error floor for each parameter $\left(5 \%, 1.42^{\circ}\right.$ and 0.025 for the apparent resistivity, phase and induction vector, respectively). Regarding the apparent resistivity, the RMS was calculated after giving the static shift that minimized the residuals of the apparent resistivity (App. Res. 2 in Table 1). The final model reduced the RMS to 4.27, 5.00, and 2.23 for the apparent resistivity, impedance phase, and induction vector, respectively. Table 1 shows that the layered structure yielded drastic reductions to the RMS for apparent resistivity and phase, and inserting the 3-D bodies improved the fit of the induction vector. We should be aware that the RMS of the induction vector is significantly smaller than those of other two parameters, and thus our model strongly depends on the induction vector. However, the RMSs of the apparent resistivity and phase were almost comparable. This implies that the modeling was unaffected by the static shift. The modeling strategy that focused on the induction vector was, therefore, effective in determining the 3-D structure.

The model remains certain degree of facultativity, because the modeling process was not based on a numerical algorism such as an inverse analysis. Thus, it is possible that there may be other models that can reproduce the measured response better. However, the distributions of the induction vector with the dense arrangement of stations allowed us to constrain accurately the horizontal extent of the conductors. We selected the final model that minimized the RMS, from a large number of models with various resistivity and geometry of the 3-D bodies. The feature of the final model is represented by three conductors (C1, $\mathrm{C} 2$ and $\mathrm{C} 3$ in Fig. 6). The measured induction vectors required that the lava dome's resistivity $(\mathrm{C} 1)$ be an order lower $(50 \Omega \mathrm{m})$ than the surrounding surface $(500$ $\Omega \mathrm{m})$. A bowl-shaped conductive layer of $50 \Omega \mathrm{m}$ below the lava dome to a depth of $150 \mathrm{~m}(\mathrm{C} 2)$ was necessary to fit the induction vectors at the frequency range of 3600 to $100 \mathrm{~Hz}$. The extent of C2 
corresponds approximately to the previous topography of the crater, as mentioned in Section 5. This conductive layer was connected to the lava dome. A conductor of 1 to $5 \Omega \mathrm{m}$ was required at a deeper zone (C3) to satisfy the fit at the frequency range of 100 to $10 \mathrm{~Hz}$. The lower limit of this conductor could not be resolved because large, regional southeastward vectors masked the local variations. In addition, the skin depth for the AMT band was not sufficient. Thus, the structure below approximately $500 \mathrm{~m}$ a.s.1. is not provided by this model. Finally, to accommodate the induction vectors at sites C50 and D50 (Fig. 3b), a conductive block of $5 \Omega \mathrm{m}$ was inserted into the northeastern area, just under the dome (C2').

These conductors were not resolved by the previous DC resistivity soundings (Watanabe et al., 1984; Sapporo District Meteorological Observatories, 1999) because these soundings assumed a layered structure and reflected the average resistivity in a certain area. The dense arrangement of the measurement sites and 3-D analysis in this study allow the discussion about such structures consisting of 3-D geometry.

\section{Discussion}

The specific three conductors (C1, C2 and C3 in Figs. 6 and 7) were detected in the final model. In this section, we discuss the role of these conductors, taking other previous studies into account. Figure 7 is shown as the interpretation of the resistivity structure corresponding to Fig. 6.

The 3-D model yielded a resistivity for the lava dome of $50 \Omega \mathrm{m}(\mathrm{C} 1)$. Because this is a relatively low value for consolidated andesitic lava, there should be some reason that reduce the resistivity. Possible causes for a conductive condition considered in volcanic area are mainly high temperature, high porosity with conductive water, partial melting and hydrothermal alteration. High temperature and partial melting are rejected because it is difficult to consider that the dome generated about 100 years ago still keeps high temperature which decrease resistivity by several orders. Both hydrothermal alteration and pore water probably causes this low resistivity of the dome. Laboratory measurements shows commonly 20-100 $\Omega \mathrm{m}$ as the resistivity of wet andesite and approximately $20 \Omega \mathrm{m}$ for altered andesite rocks under the temperature of $100^{\circ} \mathrm{C}$ (Yokoyama et al., 1983; Llera et al., 1990; Roberts et al., 1999). These resistivities approximately correspond to that of $\mathrm{C} 1$, thus it is likely that the dome has been internally altered by fumarolic gas and meteoric water penetrating through the developed fractures. In the time since the appearance of the Tarumai dome in 1909, several phreatic explosions have produced both fumaroles and fissures on the dome, and its current overall shape was established in 1933 (Ishikawa et al., 1972). Geochemical studies identified high variability in $\mathrm{CO}_{2}$ flux, soil gas pressure, and soil temperature on the dome and in fissures in the northeastern part of the crater (Hernandez et al., 2001). Because the $\mathrm{CO}_{2}$ flux and pressure gradient covaried, Hernandez et al. (2001) concluded that $\mathrm{CO}_{2}$ emission was probably controlled by Darcian flow, suggesting that fumarolic gas rises through highly fractured zones. This fact implies that a lot of fractures have been developed in the dome. It supports the interpretation that the dome has been altered by fumarolic gas and meteoric water penetrating through the fractures. A similar case to the Tarumai dome is found at La Soufrière volcano, which has a lava dome consisting of andesite as well as the Tarumai dome. An electrical tomography conducted at La Soufrière volcano showed a resistivity of more than a few hundred $\Omega \mathrm{m}$ in an area of homogeneous, unaltered rocks (Nicollin et al., 2006). At La Soufrière dome, however, a conductive layer of a few 
dozen $\Omega \mathrm{m}$ was assumed, corresponding to the active fumarolic area. This most likely resulted from hydrothermal alteration associated with the fumarolic activity and the penetration of meteoric water through radial fractures in the dome (Nicollin et al., 2006).

A bowl-shaped conductive layer of $50 \Omega \mathrm{m}$ is present beneath the lava dome down to a depth of $150 \mathrm{~m}$ below the surface (C2). This layer extends to a radius of $600 \mathrm{~m}$ from the dome and also reaches a further $200 \mathrm{~m}$ toward the northeastern part of the crater. The horizontal coverage of this layer roughly corresponds to the geography of the crater prior to the 1909 eruption (Oinouye, 1909). The conductive layer likely consists of young volcanic deposits, given that Tarumai has experienced magmatic eruptions in recent history.

This conductive layer can play a significant role for the fumarolic activity around the Tarumai dome. If this layer indicates an aquifer, the components and temperature of fumarolic gas will differ depending on the rising path. Fumarolic activity around the dome appears to vary with location relative to the bowl-shaped structure. Crater A, outside the bowl-shaped structure, and fumaroles B, on its edge, emit high-temperature gases $\left(>600^{\circ} \mathrm{C}\right.$; Sapporo District Meteorological Observatories, 2004) and have geochemical attributes that are consistent with high temperature (Ossaka et al., 1984; Geological Survey of Japan, AIST, 2004), suggesting degassing directly from magma. Temperatures of the other fumaroles were below the boiling point of water, and their chemical compositions lacked water-soluble components (Ishikawa et al., 1972). In addition, the thermal energy release-rate from crater A was estimated as $10 \mathrm{MW}$, whereas values from the other areas were less than $1 \mathrm{MW}$ (Kagiyama et al., 1984). Thermal energy is, therefore, discharged almost exclusively from crater A. Taking into account the fact that temperature of fumaroles B increased after that study (Sapporo District Meteorological Observatories, 2004), it is logical that the conduits supplying fumaroles A and B differ from those of the other fumaroles, and that the differences in fumarolic temperature and chemical composition may be a function of interaction with ground water.

Given that the bowl-shaped structure consists of young, porous volcanic material, it may be either a shallow aquifer with meteoric water, or condensed water originated from magmatic volatiles. The geochemical study supports the existence of a certain amount of water beneath the dome. According to their study, gases emitted from fumaroles A and B have characteristics of hightemperature volatiles, but gas from $\mathrm{B}$ is low in $\mathrm{HCl}$. This was attributed to interaction of gas in the B fumaroles with meteoric ground water beneath the lava dome, supplied by rainfall trickling through fractures (Ossaka et al. 1984).

This assumption of the aquifer requires the presence of an impermeable layer below the watersaturated layer in order to prevent water loss. Both two independent structures can act as impermeable layer: (1) $500 \Omega \mathrm{m}$ of the layer surrounding the $\mathrm{C} 2$ and (2) $1-5 \Omega \mathrm{m}$ of the conductive body below $\mathrm{C} 2$. We discuss these structures independently.

(1) According to Oinouye (1909), small ponds were present in the crater area prior to the 1874 eruption. These disappeared, probably as a result of crater-wall collapse. This indicates that a certain amount of meteoric water can be collected in the crater, and that an impermeable unit must lie beneath the young volcanic deposits. The material beyond the bowl-shaped structure consists of older volcanic deposits with comparatively low porosity, as evidenced by their high resistivity $(500 \Omega \mathrm{m})$. This older deposit may act as the impermeable layer.

(2) The bottom of the bowl-shaped structure contacts with extremely low-resistivity bodies

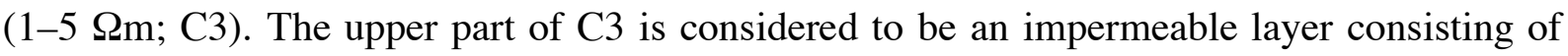


hydrothermally altered clay. This part corresponds to the vent, its surroundings and the root of the dome. During the past eruptions, this has been repeatedly heated and exposed to volcanic fluids, and such a condition is suitable to develop alteration. Similar interpretations are documented from other volcanoes. It is likely that such a conductor accounts for the characteristic resistivity structure beneath volcanic crater lakes. For example, Kanda et al. (2008) assumed the presence of a conductor of a few $\Omega \mathrm{m}$ beneath the crater lake of Aso volcano. They interpreted the upper part of the conductor as the impermeable layer, which had been hydrothermally altered and acted as the bottom of the crater lake. Nurhasan et al. (2006) also referred to an altered, impermeable layer beneath the crater lake of Kusatsu-Shirane volcano. In case of the Tarumai, the aquifer formed by the bowl-shaped structure may be considered to be a sort of "buried crater lake."

Another conductive zone (1-5 $\Omega \mathrm{m}, \mathrm{C} 2$ ') is assumed to extend northeastward from the bowlshaped structure. This zone is beneath fumaroles $\mathrm{F}$ and geothermal area $\mathrm{L}$ that is coincident with northeast-trending fissures. It is likely that this conductor corresponds to a hydrothermally altered area along a fracture zone beneath the fissures. Miyamura et al. (1995) and Miyamura (2004) reported a positive anomaly $(>100 \mathrm{mV})$ in the self-potential (SP) at this area. SP anomaly is generally explained by the electrokinetic effects, which is driven by the fluid flow. A positive SP anomaly is often seen over hydrothermal upwelling, whereas mounded topography produces a terrain-related anomaly, which shows a negative correlation to the elevation. In many cases of volcanic fields, superposition of two anomalies results in the "W-shape" SP profile. The SP anomaly at C2' area was distinct from the anomaly represented by the entire volcano, and suggested that hydrothermal fluid was also flowing upward in this area (Miyamura, 2004). In addition, the soil $\mathrm{CO}_{2}$ flux and temperature were higher there than in other parts of the crater, indicating some localized supply of fluids (Hernandez et al., 2001). Considering these facts, there should be some hot flow in this area and it may have developed the hydrothermal alteration and resulting low resistivity.

Conductive bodies (C3) beneath the southeastern half of the dome and eastern part of the crater are probably associated with the vent area of past eruptions. It is a possible interpretation that hydrothermal fluids are ascending here. The extremely low resistivity (1-5 $\Omega \mathrm{m}$ ) of C3 may be brought by complex causes regarding upward flow of volcanic fluids. Similar conductors of a few $\Omega \mathrm{m}$ are present at depths of several hundred meters beneath the craters of other active volcanoes. Mogi and Nakama (1993) concluded that the physical conditions associated with a low-resistivity zone were archived by high porosity, pervasive alteration, and high temperature in an area where volumes of convecting hydrothermal fluid were flowing upward. The conductor $\mathrm{C} 3$ in this study also corresponds to the location where hydrothermal fluids rise through the vent area. This idea is supported by a SP investigation. Miyamura et al. (1995) estimated the depth of a positive current source from the measured SP distribution in the crater area of Tarumai to be approximately $500 \mathrm{~m}$ a.s.l., assuming that it was present only beneath the lava dome. If the source of the self-potential is rising hydrothermal fluids, the location of the source would indicate an upper depth limit for upward fluid movement (Miyamura et al., 1995). The estimated depth corresponds to the central part of the conductor, although the conductor is unevenly distributed on the eastern side of the lava dome. Given that the distribution of the positive SP anomaly corresponds to this area, it is likely that hydrothermal fluids are ascending in the area of C3. Thus, this conductor, together with the interpretation of Mogi and Nakama (1993), identifies the zone of upward flow. This concurs with 
the idea that an altered impermeable layer forms the upper part of the conductor (C3) and acts as a cap that suppresses the ascent of hydrothermal fluids.

Hot volcanic gases probably rise without contacting water, because gases measured at the surface have not lost water-soluble components. Although a vapor-phase fluid generally acts as a high-resistivity body, the resistivity model did not detect a high-resistivity zone beneath the lava dome. Aoyama (2006) proposed that superheated vapor associated with low-frequency earthquake swarms at about sea level beneath the lava dome ascended to the surface and vented through hightemperature fumaroles. The conduit size assumed as the fluid path by Aoyama (2006) is quite small (10 $\mathrm{m}$ radius) compared to the smallest size of grid elements in the model, and so it is possible that the resolution of the resistivity model was not adequate for detecting a small resistive zone beneath the lava dome.

The arguments above suggest that the following events occur in a stationary volcanic fluid system beneath the crater area of Tarumai volcano (Fig. 7). High-temperature volcanic gas vaporized from magma ascends through a path in the conductor (C3). During ascent, the volcanic gas heats ground water and drives hydrothermal convection. The impermeable, altered layer at the top of the conductor (C3) prevents further movement of hydrothermal fluids. Some hightemperature gas penetrates this layer and loses water-soluble components by interacting with a shallow aquifer, such as a "buried crater lake" (C2), before finally emerging at low-temperature fumaroles around the lava dome. Most of gas is diverted away from the shallow aquifer (C2), resulting in release of high-temperature gas from crater A and fumaroles B.

These interpretations may be helpful in understanding changes in volcanic activity. Geographic positioning system and total magnetic force measurements around Tarumai volcano show inflation and demagnetization, respectively, from 1999 to 2000. Both phenomena began beneath the lava dome at around $700 \mathrm{~m}$ a.s.l. (Seismology and Volcanology Research Department, MRI, 2008), corresponding approximately with the boundary between conductors $\mathrm{C} 2$ and $\mathrm{C} 3$. Inflation and heating occurred simultaneously beneath the lava dome. This phenomenon reflects thermal expansion or pore-pressure increase caused by adding volcanic fluid at the bottom of the conductor (C2), and thus implies a possibility that the fluid path had been changed to heat the shallow aquifer (C2) preferentially. However, thermal activity grew overall in the crater area because the fumarolic temperature of crater $\mathrm{A}$, which was located outside the $\mathrm{C} 2$, increased from 200 to $600^{\circ} \mathrm{C}$ at the same time (Sapporo District Meteorological Observatories, 2004). One of more plausible interpretation is that the hot fluid supply from deeper part of the volcano temporary increased and heated the bottom of the shallow aquifer.

\section{Conclusions}

The relationship between the subsurface structure and fumarolic activity in the vicinity of a lava dome was investigated using an AMT survey of the crater area of Tarumai volcano. Threedimensional resistivity modeling was performed to achieve this purpose. Estimation of the topographic effect showed that induction vectors pointed toward the center of the dome, but did not fully explain the measured vectors. This suggested that the distribution of induction vectors could be a helpful parameter in determining the geometry of the conductive body, even in a situation that is complicated by steep topography. Three-dimensional analysis that incorporates topography may 
yield the true subsurface structure.

The model identified two main conductive bodies beneath the lava dome (C2 and $\mathrm{C} 3$ in Fig. 6). The shallower body is likely an aquifer such as a buried crater lake. The deeper, extremely conductive body corresponds with a convecting zone of fluid ascent. Some high-temperature gas loses its water-soluble components and heat during encounter with the shallow aquifer and is released in low-temperature fumaroles around the lava dome. Most of gas, however, rises outside the area of the shallow aquifer and is emitted at high-temperature fumaroles. This 3-D resistivity structure can contribute to the accuracy of hydrothermal models, helping us understand the heatsupply system of Tarumai volcano. Study of the hydrological balance in the crater area will be required to corroborate these results.

\section{Acknowledgments}

We would like to express our appreciation to Prof. M. Kasahara and Dr. H. Hase at Hokkaido University for many valuable suggestions regarding the content of this paper. We are grateful to Prof. M. Ingham and an anonymous reviewer for constructive criticism that greatly improved the manuscript. We are also grateful to Mr. A. Suzuki and Mr. T. Watanabe for their assistance in the field. Some of the figures were created using the software package Generic Mapping Tools (GMT; Wessel and Smith, 1998). This paper is part of a doctoral thesis submitted by author Yamaya to Hokkaido University, 2008.

\section{References}

Aizawa, K., Y. Ogawa, T. Hashimoto, T. Koyama, W. Kanda, Y. Yamaya, M. Mishina, T. Kagiyama, 2008. Shallow resistivity structure of Asama Volcano and its implications for magma ascent process in the 2004 eruption, J. Volcanol. Geotherm. Res. 173, 165-177.

Aoyama, H., 2006. Seismic swarm and emission of high temperature gas at Tarumae volcano induced by the 2003 Tokachi-oki earthquake, Abstracts, Japan Geoscience Union Meeting 2006 (CD-ROM), V101-P001.

Aoyama, H., H. Oshima, A. Suzuki, T. Maekawa, 2004. Recent seismic activities at active volcanoes in Hokkaido-Tarumaesan-, Geophysical Bulletin of Hokkaido University 67, 111-129 (in Japanese, with English Abstr.).

Caldwell, T., H. M. Bibby, C. Brown, 2004. The magnetotelluric phase tensor, Geophys. J. Int. 158, 457-469.

Fomenko, E.Y., Mogi, T., 2002. A new computation method for a staggered grid of 3D EM field conservative modeling, Earth, Planets Space 54, 499-509.

Gamble, T. D., W. M. Goubau, J. Clarke, 1979. Magnetotellurics with a remote magnetic reference, Geophysics 44, 53-68.

Groom, R. W, Bailey, R. C., 1989. Decomposition of magnetotelluric impedance tensors in the presence of local three dimensional galvanic distortions, J. Geophys. Res. 94, 1913-1925.

Geological Survey of Japan, AIST, 2004. Observation report of volcanic gas at the Tarumai volcano, Conference material for the 99th meeting of Coordinating Committee for Prediction of Volcanic Eruption, WWW Page http://www.gsj.jp/kazan/kazan-bukai/yochiren/099/gas_tarumai.pdf (in Japanese). 
Hernandez, P. A., G. Natale, F., Tsunomori, K. Sugiyama, T. Ito, K. Notsu, H. Okada, N. Pérez, 2001. Preliminary results of diffuse emission of $\mathrm{CO}_{2}$ and soil gas pressure gradient measurements at Tarumae Volcano, Japan, Bull. Volcanol. Soc. Japan 46, 121-125.

Ishikawa, T., I. Yokoyama, Y. Katsui, 1972. Tarumai-san, its volcanic geology, history of eruption, present state of activity and prevention of disasters, Committee for Prevention of Disasters of Hokkaido, Sapporo, pp. 124 (in Japanese).

Jones, K. A., M. R. Ingham, H. M. Bibby, 2008. The hydrothermal vent system of Mount Ruapehu, New Zealand-A high frequency MT survey of the summit plateau, J. Volcanol. Geotherm. Res. 176, 591-600.

Kagiyama, T., N. Osada, T. Maekawa, A. Suzuki, 1984. Thermal survey of the Tarumai volcano-Analysis of infrared imagery and successive photographs of fumarolic plume-, Joint Geophysical and Geochemical Observations of Usu Volcano in 1982 and the Tarumai Volcano in 1983, 191-206 (in Japanese, with English Abstr.).

Kagiyama, T., H. Utada, T. Yamamoto, 1999. Magma ascent beneath Unzen Volcano, SW Japan, deduced from the electrical resistivity structure, J. Volcanol. Geotherm. Res. 89, 35-42.

Kanda W., Y. Tanaka, M. Utsugi, S. Takakura, T. Hashimoto, H. Inoue, 2008. A preparation zone for volcanic explosions beneath Naka-dake crater, Aso volcano, as inferred from magnetotelluric surveys, J. Volcanol. Geotherm. Res. 178, 32-45.

Katsui, Y., 1963. Evolution and magmatic history of some Krakatoan calderas in Hokkaido, Japan, $J$. Fac. Sci., Hokkaido Univ., ser. 4, 11, 631-650.

Llera, F. J., M. Sato, K. Nalkatsuka and H. Yokoyama, 1990. Temperature dependence of the electrical resistivity of water-saturated rocks, Geophysics, 55, 576-585.

Matsushima, N., H. Oshima, Y. Ogawa, S. Takakura, H. Satoh, M. Utsugi, Y. Nishida, 2001. Magma prospecting in Usu volcano, Hokkaido, Japan, using magnetotelluric soundings, J. Volcanol. Geotherm. Res. 109, 263-277.

Miyamura, J., Y. Tajima, Y. Yamauchi, K. Tamura, 1995. Self-potential measurement in Tarumae Volcano, Quarterly Journal of Seismology 58, 79-90 (in Japanese, with English Abstr.).

Miyamura, J., 2004. Repeated measurements of self-potential in Tarumae volcano, Hokkaido, Japan, Geophysical Bulletin of Hokkaido University 67, 137-148 (in Japanese, with English Abstr.).

Mogi, T., Nakama, S., 1993. Magnetotelluric interpretation of the geothermal system of the Kuju volcano, southwest Japan, J. Volcanol. Geotherm. Res. 56, 297-308.

Müller, A., Haak, V., 2004. 3-D modeling of the deep electrical conductivity of Merapi volcano (central Java): Integrating magnetotellurics, induction vectors and the effects of steep topography, J. Volcanol. Geotherm. Res. 138, 205-222.

Nam, J. M., H. Kim, Y. Song, T. J. Lee, J. Son, J. H. Suh, 2007. 3D magnetotelluric modelling including surface topography, Geophysical Prospecting 55, 277-287.

Nicollin, F., D. Gibert, F. Beauducel, G. Boudon, J. C. Komorowski, 2006. Electrical tomography of La Soufrière of Guadeloupe Volcano: Field experiments, 1D inversion and qualitative interpretation, Earth and Planetary Sci. Letters 244, 709-724.

Nurhasan, Y. Ogawa, N. Ujihara, S. B. Tank, Y. Honkura, S. Onizawa, T. Mori, M. Makino, 2006. Two electrical conductors beneath Kusatsu-Shirane volcano, Japan, imaged by audiomagnetotellurics, and their implications for the hydrothermal system, Earth Planets Space 58, 1053-1059.

Oinouye, Y., 1909. A report of the 1909 eruption of Tarumai volcano, Rep. Imp. Earthquake Inv. 
Com. 64, 1-23 (in Japanese).

Ossaka, J., J. Hirabayashi, T. Ozawa, T. Abiko, 1984. Chemical Compositions of Volcanic Gases from the Tarumai volcano in 1983, Joint Geophysical and Geochemical Observations of Usu Volcano in 1982 and the Tarumai Volcano in 1983, 207-209 (in Japanese, with English Abstr.).

Roberts, J. J., Bonner, B. P., and Duba, A. G., 1999. Electrical Resistivity Measurements of Brinesaturated Porous Media Near Reservoir Conditions: Awibengkok Preliminary Results, Geothermal Resources Council Transactions, 23, 35-39.

Sapporo District Meteorological Observatory, 1999. Tarumae, Esan, Hokkaido-Komagatake and Meakandake, Report of Mobile Volcano Observation Team of Hokkaido District 20, 118 pp. (in Japanese).

Sapporo District Meteorological Observatory, Meakan-dake, Tokachi-dake, Tarumae, Usu and Hokkaido Komagatake, 2004. Report of Mobile Volcano Observation Team of Hokkaido District 24, 154pp. (in Japanese).

Seismology and Volcanology Research Department, MRI, 2008. Studies on evaluation method of volcanic activity, Technical Reports of the Meteorological Research institute, Japan 53, 306 pp. (in Japanese, with English Abstr.).

Terada, A., M. Nakagawa, H. Oshima, H. Aoyama, H. Kamiyama, 2004. Weak glow witnessed by the high-sensitive camera at Tarumae volcano, Japan soon after the Tokachi-oki Earthquake in $2003\left(\mathrm{M}_{\mathrm{JMA}} 8.0\right)$, Bulletin of the Earthquake Research Institute 79, 17-26 (in Japanese, with English Abstr.).

Watanebe, H., Hm. Okada, T. Maekawa, A. Suzuki, 1984. Measurements of electrical resistivity at the summit of the Tarumai volcano in 1983, Joint Geophysical and Geochemical Observations of Usu Volcano in 1982 and the Tarumai Volcano in 1983, 177-184 (in Japanese, with English Abstr.).

Wessel, P., Smith, W. H. F., 1998. New, improved version of Generic Mapping Tools released, EOS Trans. Amer. Geophys. U. 79, 579 pp.

Yamaya, Y., T. Hahsimoto, T. Mogi, A. Suzuki, Y. Nishida, K. Tanimoto, H. Mori, A. Terada, M. Mishina, H. Hase, 2005. Wide-band MT Survey on the Tarumai volcano, Hokkaido: 2-D Resistivity Analysis, Geophysical Bulletin of Hokkaido University 68, 127-140 (in Japanese, with English Abstr.).

Yokoyama, H., K. Nakatsuka, M. Abe and K. Watanabe, 1983. Temperature dependency of electrical resistivity of water saturated rocks and the possibility of underground temperature estimation, Journal of Geothermal Research Sciety of Japan, 5, 103-120, (in Japanese, with English Abstr.).

Yokoyama, I., 2004. Formation processes of the 1909 Tarumai and the 1944 Usu lava domes in Hokkaido, Japan, Annals of Geophysics 47, 1811-1825. 


\section{Figures}

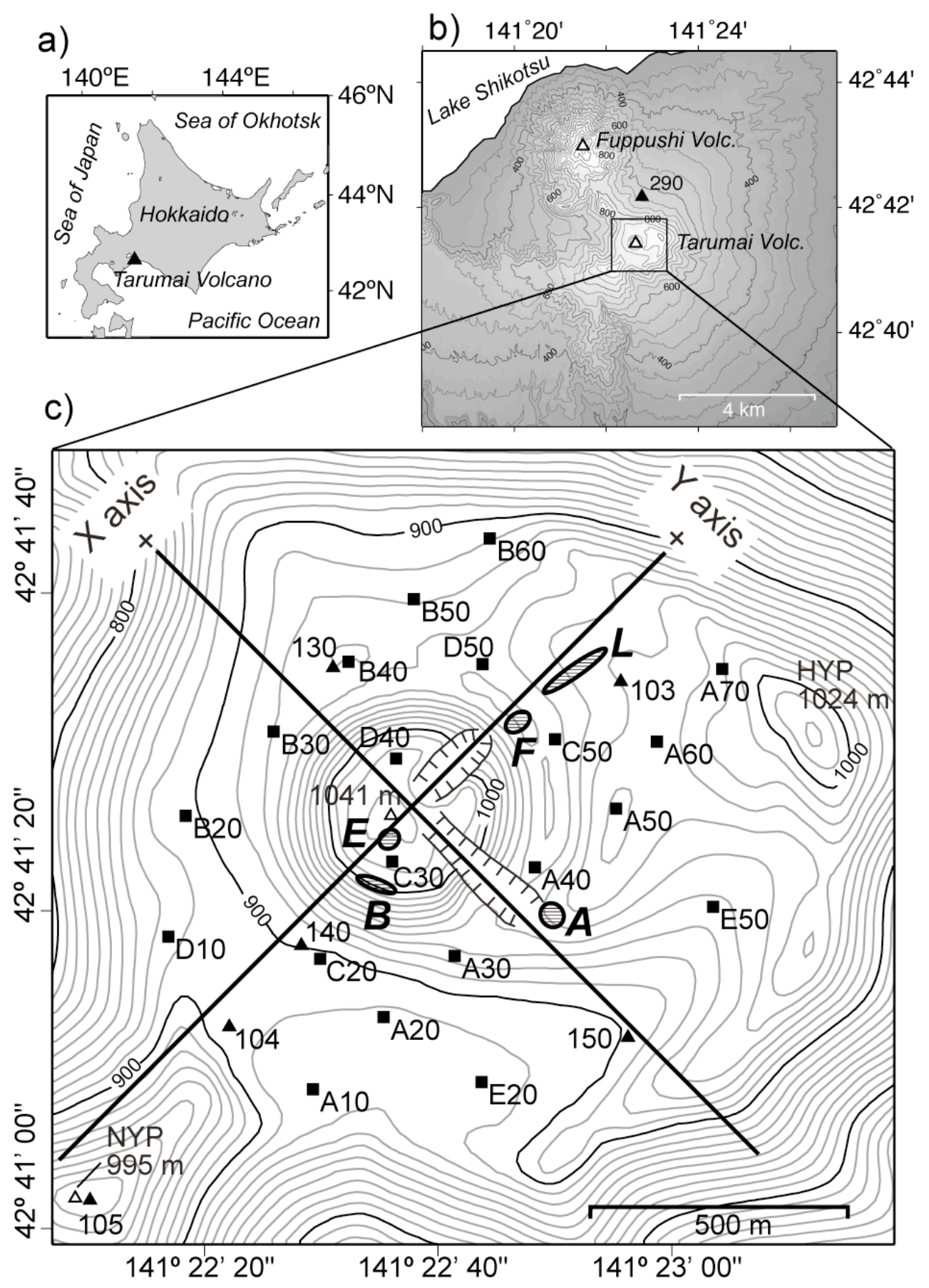

Fig. 1. (a) Hokkaido, Japan and (b) regional setting of Tarumai volcano with the site 290 which was referenced as the remote site. (c) Geographic setting and distribution of AMT measurement sites in the crater area of Tarumai volcano. Solid squares and triangles indicate AMT sites (this study) and wideband-MT sites (Yamaya et al., 2005), respectively. Open triangles show significant volcanic peaks. Hatched areas represent active fumarolic zones: crater A, fumaroles B, E, and F, and geothermal fissure L. Lines flagged by $\mathrm{X}$ and $\mathrm{Y}$ axes indicate the coordinate system for the 3-D modeling. 

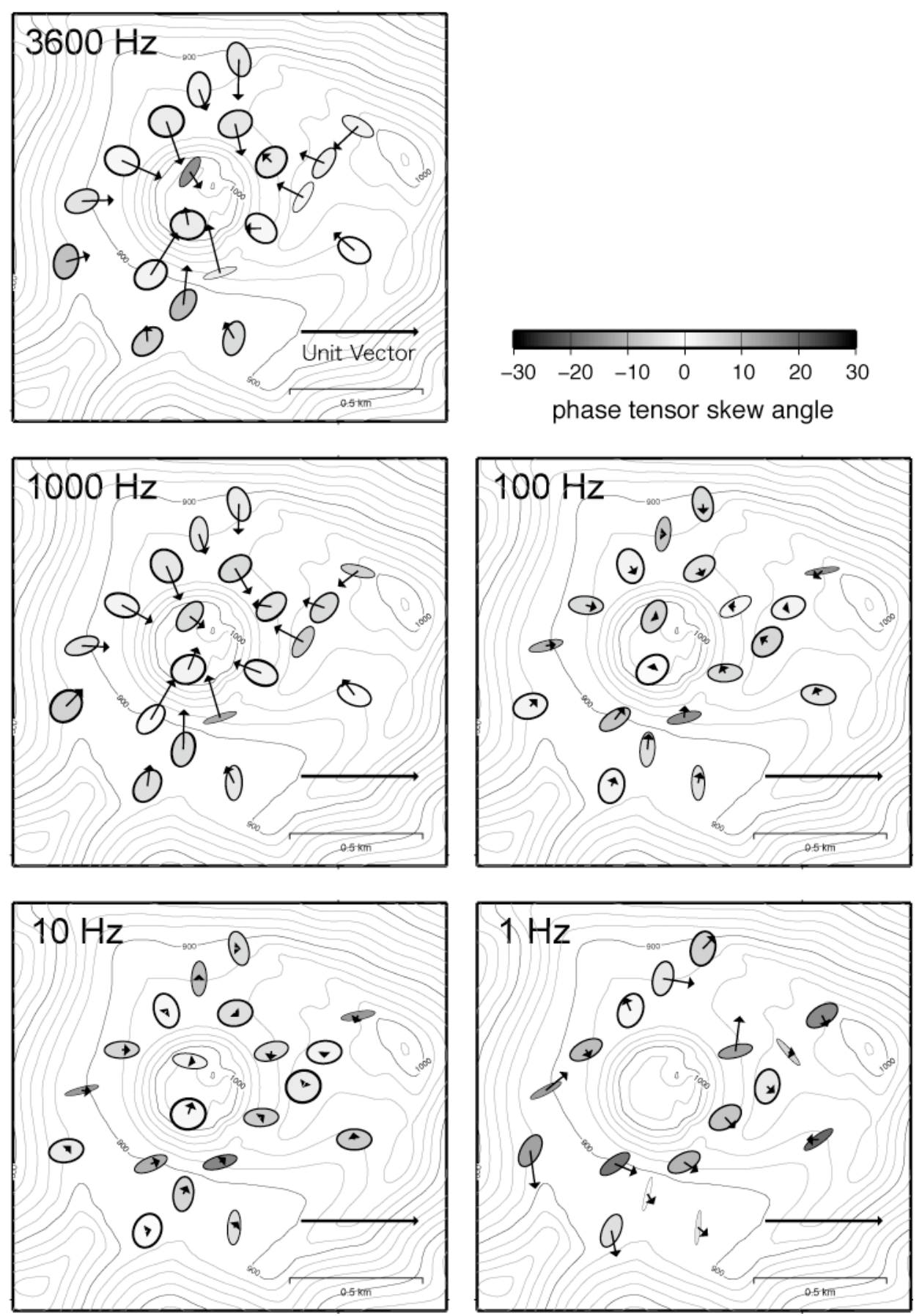

Fig. 2. Distribution of measured induction vectors and phase tensors at each frequency. Arrows represent the induction vectors and ellipses represent the phase tensors. The gray scale indicates the skew angle (degree) of the phase tensor. 

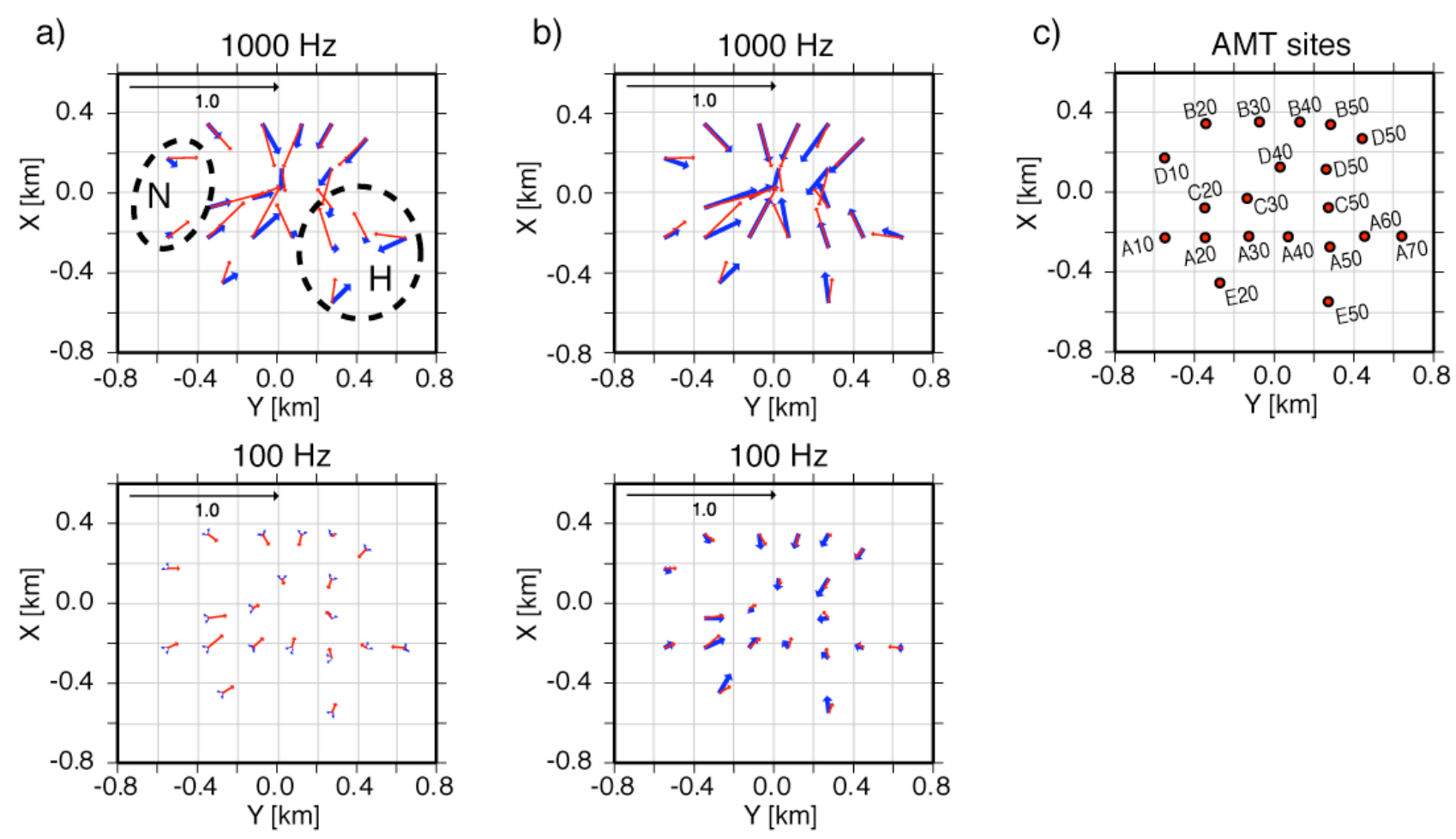

Fig. 3. The distribution of the measured (red) and calculated (blue) induction vectors at frequencies of 1000 and $100 \mathrm{~Hz}$. a) Calculation assuming uniform resistivity and incorporating the topography of the crater area. Areas circled by a broken line $(\mathrm{N}$ and $\mathrm{H})$ show MT sites affected by the steep peaks. b) Induction vectors calculated from the final model. Conductive bodies were inserted into the layered structure (Fig. 4). c) Corresponding AMT site locations with station names.

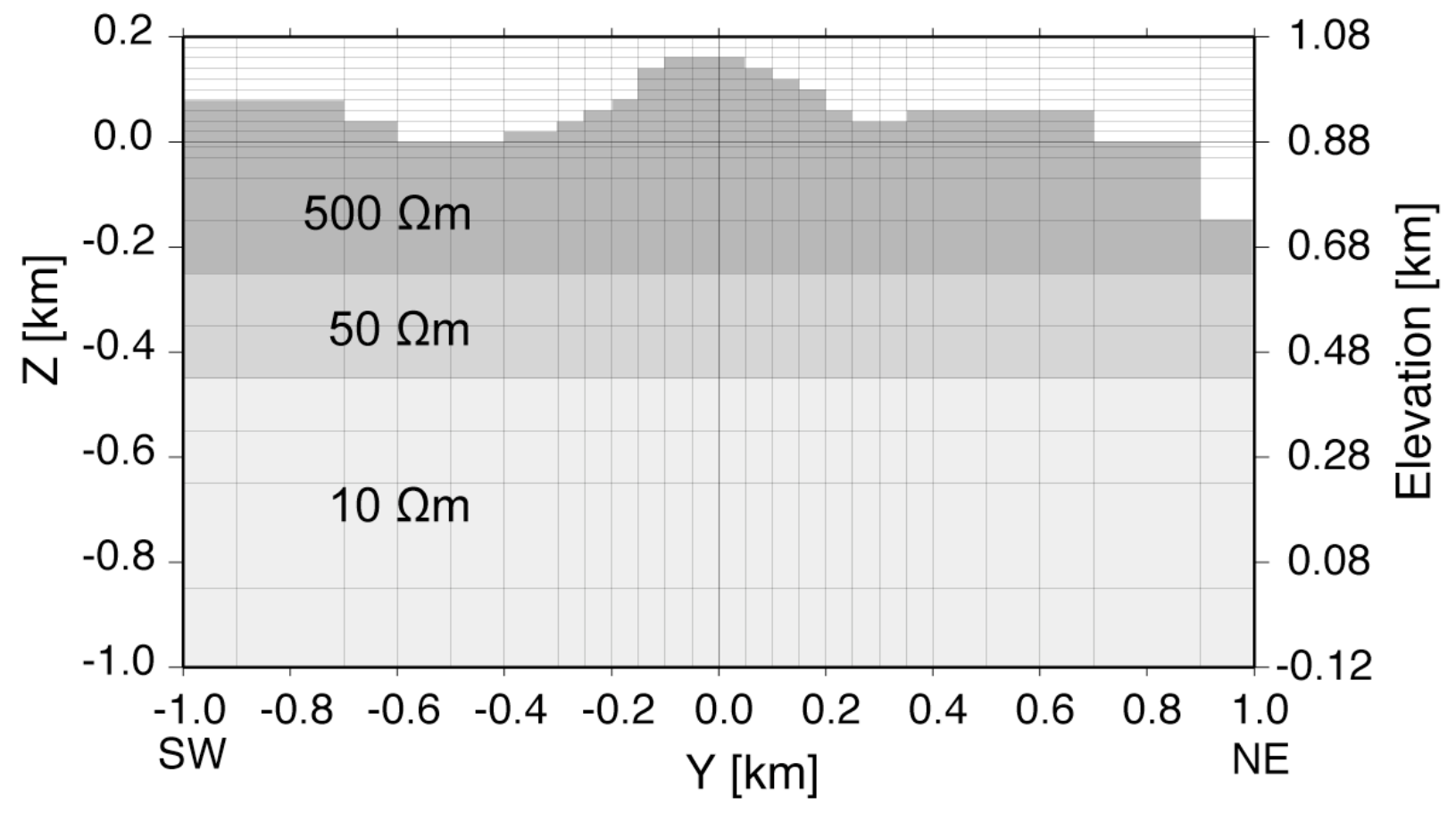

Fig. 4. A quasi-1-D structure was the basis for 3-D modeling. The resistivity section beneath the $\mathrm{X}$ axis (see Fig. 1) is shown. 

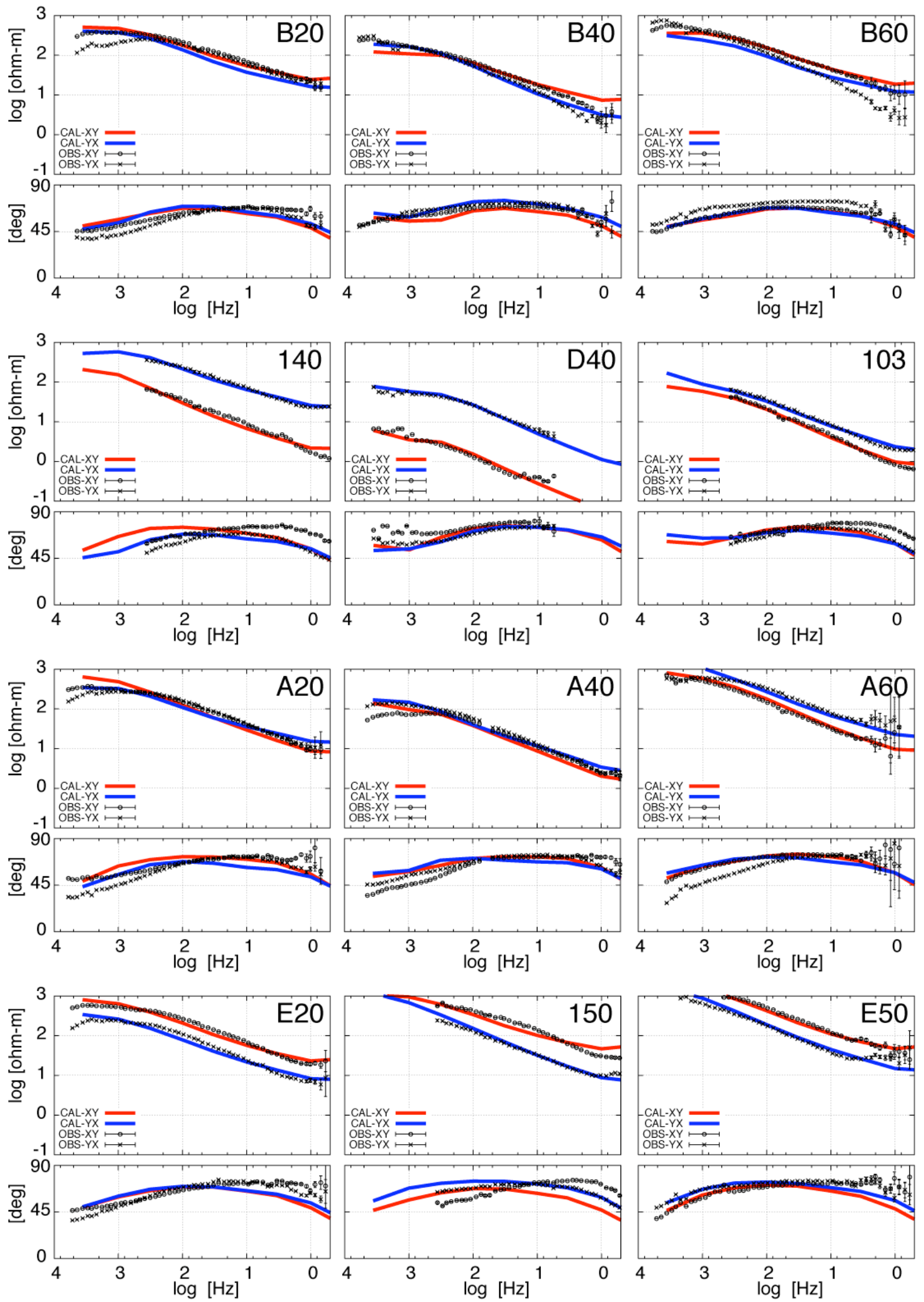

Fig. 5. Comparison of the calculated and observed apparent resistivity and impedance tensors at representative sites. Dots with error bars and solid lines indicate the measured and calculated responses, respectively. Red and blue symbols show the xy and yx components, respectively. The coordinate system corresponds to the $\mathrm{X}$ and $\mathrm{Y}$ axes shown in Fig. 1. 


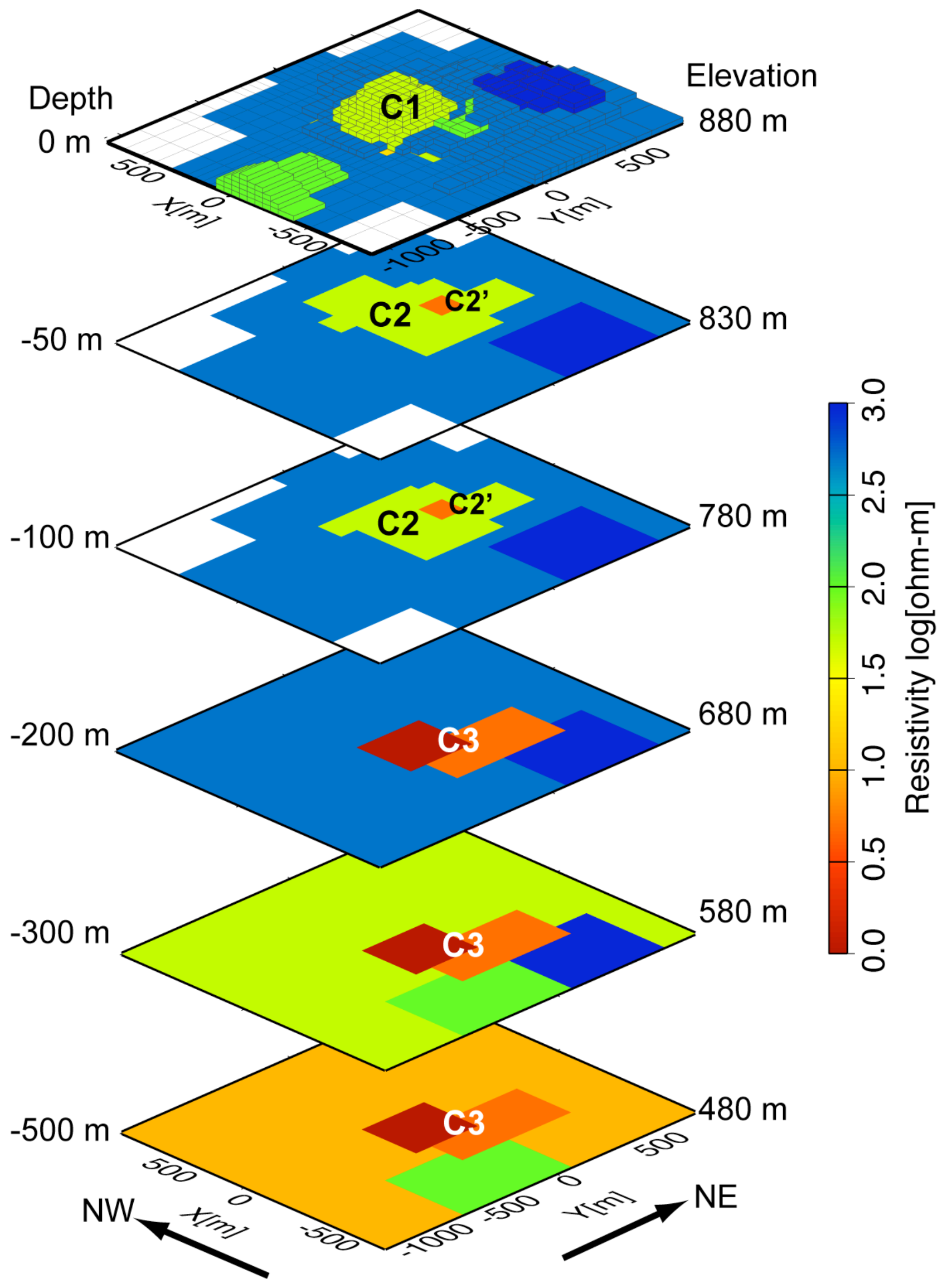

Fig. 6. Final model of 3-D resistivity beneath the crater area of Tarumai volcano. The model shows the horizontal distribution of resistivity at each elevation. 


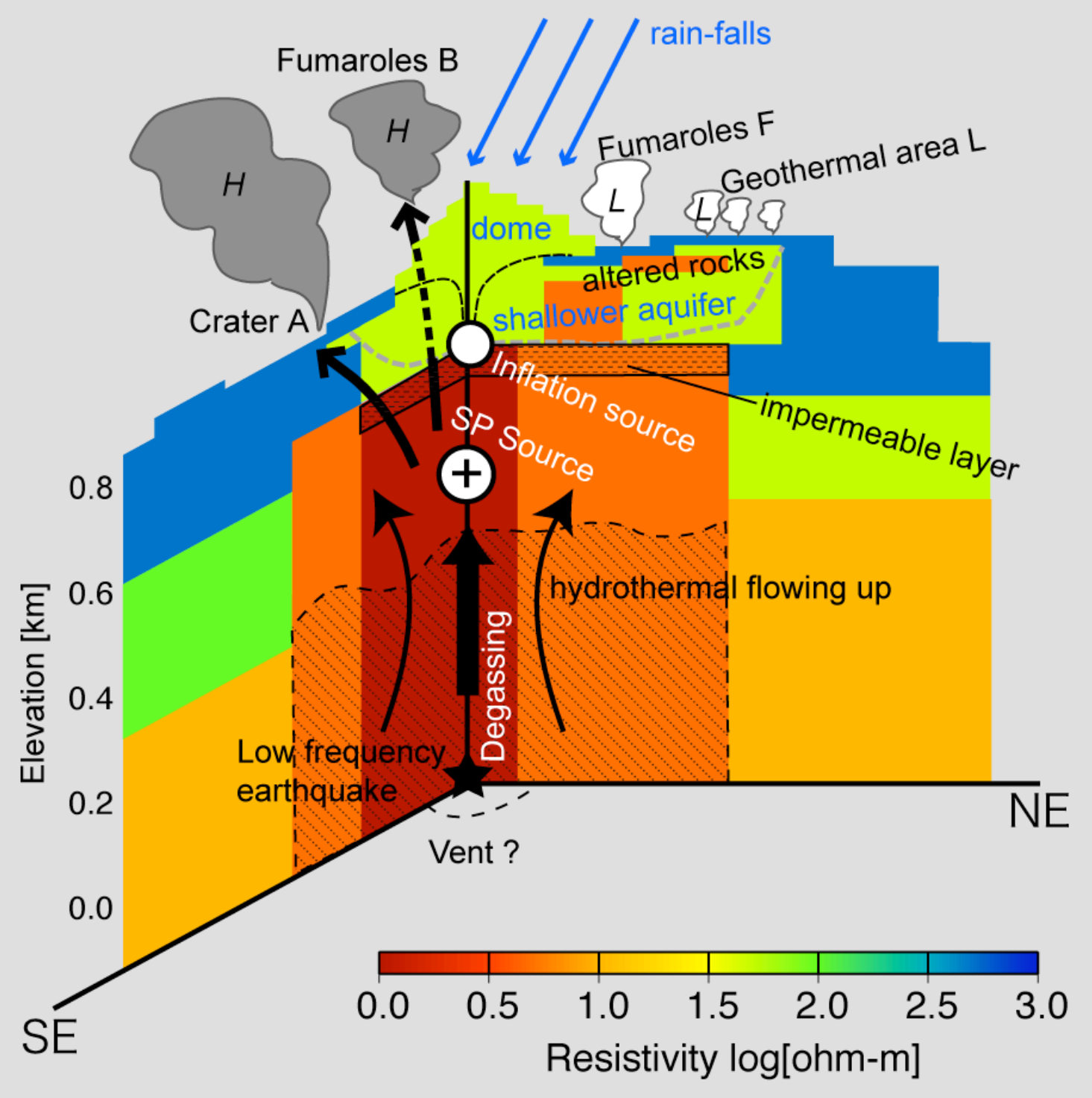

Fig. 7. Schematic model of the hydrothermal system around the lava dome of Tarumai volcano. The locations of the inflation and self-potential sources are after those reported by the Seismology and Volcanology Research Department, MRI (2008) and Miyamura et al. (1995), respectively.

Table 1. The root mean-square (RMS) residual for different models. All models included surface topography. "Uniform $100 \Omega \mathrm{m}$ " corresponds to the model assumed in Section 4.2. The "Layered structure" and "Final model" are shown in Figs. 4 and 6, respectively. "App. Res. 1" and "2" are the RMS residuals of apparent resistivity without and with considering the static shift, respectively.

\begin{tabular}{ccccc}
\hline Model & App. Res. 1 & App. Res. 2 & Impedance phase & Induction vector \\
Uniform 100 $\Omega \mathrm{m}$ & 24.1 & 14.5 & 12.5 & 3.89 \\
Layered structure & 16.6 & 4.68 & 5.56 & 3.28 \\
Final model & 12.3 & 4.27 & 5.00 & 2.23 \\
\hline
\end{tabular}

